\title{
Resolution of Experimental Pulmonary Emboli with Heparin and Streptokinase in Different Dosage Regimens
}

\author{
J. F. Cade, J. Hirsh, E. Regoeczi, M. Gent, M. R. Buchanan, and \\ D. M. HYNES \\ From the Departments of Pathology, Medicine, Clinical Epidemiology and \\ Biostatistics, and Radiology, McMaster University, Hamilton, Ontario, Canada
}

\begin{abstract}
A BSTRACT Thrombolytic agents may be useful in acute pulmonary embolism, but their optimal dosage remains uncertain. We have examined the relative efficacy of heparin and different doses of streptokinase, either alone or in combination, in acute experimental pulmonary embolism. A standardized massive embolus of autologous blood clot incorporating canine $\left[{ }^{125} \mathrm{I}\right]$ fibrinogen was given to 40 dogs; the degree of resolution after $24 \mathrm{~h}$ was quantitated by measuring the radioactivity in the lungs and was compared with detailed postmortem observations.

The amount of residual embolus was $49 \%$ in control animals, 28\% after heparin (200 U/kg loading dose and $800 \mathrm{U} / \mathrm{kg} / 24 \mathrm{~h}$ maintenance dose), and $6 \%$ after high dose streptokinase $(250,000 \mathrm{U}$ loading dose and $100,000 \mathrm{U} / \mathrm{h}$ maintenance dose); it was $31 \%$ after low dose streptokinase $(25,000 \mathrm{U}$ loading dose and 10,000 $\mathrm{U} / \mathrm{h}$ maintenance dose), $7 \%$ after low dose streptokinase with heparin, $14 \%$ after very low dose streptokinase $(5,000 \mathrm{U} / \mathrm{h}$ without a loading dose) with heparin, and $9 \%$ after short course streptokinase $(250,000$ $\mathrm{U}$ loading dose and no maintenance dose) with heparin.

The combination of heparin and low doses or brief courses of streptokinase appeared to be synergistic and produced as much resolution as did standard high dose streptokinase alone. The enhanced resolution of pulmonary emboli in heparin-treated animals may have been due to the prevention by heparin of further deposition of fibrin on the embolus. It appears that dosage regimens of thrombolytic therapy other than those in current use may be worthy of clinical examination.
\end{abstract}

This work was presented in part at the 45th Scientific Sessions of the American Heart Association, Dallas, Tex., 16-19 November 1972 (1).

Received for publication 1 November 1973 and in revised form 14 June 1974.

\section{INTRODUCTION}

Thrombolytic agents have theoretical advantages over conventional anticoagulant drugs in the treatment of acute pulmonary embolism. Thus, although heparin has been shown to be clinically effective $(2-6)$ and to reduce mortality ( 7$)$, thrombolytic agents have the potential advantage of producing accelerated lysis of the emboli (8). The use of streptokinase (SK) ${ }^{1}$ and urokinase has been investigated in both experimental (913) and clinical (14-21) venous thrombosis and pulmonary embolism, and direct comparisons have confirmed that greater early resolution occurs after thrombolytic therapy than after heparin in both experimental (22) and clinical $(21,23)$ pulmonary embolism.

There is little information, however, concerning the optimal dosage regimens of SK or urokinase administration. In 1959, Johnson and McCarty (11) showed that intermediate maintenance doses of SK were more effective than high doses in producing lysis of experimental venous thrombi in man. Nevertheless, in most recent clinical studies, SK has been given in a standard high dosage regimen designed to produce rapid and sustained plasminogen depletion and a demonstrable systemic fibrinolytic state $(24,25)$.

We have developed a model of experimental pulmonary embolism in dogs which permits quantitation of the degree of lysis of the emboli (26). This model has been used to compare the relative efficacy of heparin, SK in standard dosage, SK in lower dosage, and combinations of heparin and lower doses or briefer courses of SK.

${ }^{1}$ Abbreviations used in this paper: CTA, Committee on Thrombolytic Agents; FDP, fibrin degradation products; PTT, partial thromboplastin time; SK, streptokinase; TT, thrombin clotting time. 


\section{METHODS}

\section{Animals}

Adult mongrel dogs of average weight $19 \mathrm{~kg}$ (range 10$29 \mathrm{~kg}$ ) of either sex were used. They had been quarantined for at least $3 \mathrm{wk}$ and had been vaccinated against distemper and canine hepatitis. All were in gond clinical health and no evidence of cardiopulmonary disease was found at subsequent autopsy.

\section{Fibrinogen}

Canine fibrinogen was prepared as described elsewhere (27) and was over $90 \%$ clottable. $10 \mathrm{mg}$ of fibrinogen was labeled with approximately $500 \mu \mathrm{Ci}$ of ${ }^{120} \mathrm{I}$ by the iodine monochloride technique (28); it was subsequently diluted with $90 \mathrm{mg}$ of unlabeled fibrinogen and divided into 10 aliquots (each containing $10 \mathrm{mg}$ of fibrinogen and approximately $50 \mu \mathrm{Ci}$ of ${ }^{125} \mathrm{I}$ ) which were frozen at $-70^{\circ} \mathrm{C}$.

\section{Embolus}

A standardized massive embolus was given to each animal $(26,29)$. Autologous blood ( $1.5 \mathrm{ml} / \mathrm{kg}$ of body weight) was taken $24 \mathrm{~h}$ before embolization into anticoagulant ( 9 parts of blood to 1 part of $3.8 \%$ trisodium citrate) and allowed to stand for $6 \mathrm{~h}$ at $20^{\circ} \mathrm{C}$ to permit decay of spontaneous fibrinolytic activity and thus to prevent in vitro lysis of the clot before embolization. The blood was then thoroughly mixed with a dose of labeled fibrinogen and an aliquot of $0.1 \mathrm{ml}$ taken to prepare a standard for calculation of the total amount of radioactivity injected. The labeled blood was rapidly mixed with calcium $(0.1 \mathrm{ml} 0.25$ M calcium chloride per $10 \mathrm{ml}$ of blood) and thrombin (bovine origin, Parke, Davis \& Company, Detroit, Mich.) (10 $\mathrm{U}$ per $10 \mathrm{ml}$ of blood) and run into a long, thin-walled, polythene tube of $5 \mathrm{~mm}$ ID, where it was permitted to clot and to retract over $18 \mathrm{~h}$ at $20^{\circ} \mathrm{C}$.

\section{Anesthesia}

The animals were tranquillized with acepromazine maleate (Atravet, Ayerst Laboratories, Montreal, Quebec, Canada), $2.5 \mathrm{mg} / \mathrm{kg}$ by intramuscular injection $\frac{1}{2} \mathrm{~h}$ before venesection or general anesthesia. Light general anesthesia was induced with sodium pentobarbital (Nembutal, Abbott Laboratories, Montreal, Que.), $20 \mathrm{mg} / \mathrm{kg}$ by intravenous injection, and was continued for the duration of the experiment $(24 \mathrm{~h})$ with a dose of $2.5 \mathrm{mg} / \mathrm{kg} / \mathrm{h}$ given by continuous infusion from a syringe pump (model 942, Harvard Apparatus Co., Inc., Millis, Mass.).

\section{Embolization}

The tube containing the labeled clot was introduced via the left femoral vein to the junction of the inferior vena cava and the right atrium. A catheter (Intramedic PE 320, Clay Adams, Div. of Becton, Dickinson \& Co., Parsippany, N. J.) was introduced via the right external jugular vein into the right atrium for blood sampling and for administration of anesthetic and drugs. The embolus was delivered as a single bolus by means of a saline-filled syringe connected to the free end of the tube containing the labeled clot.

\section{Drug regimens}

All drugs were given by continuous infusion from the syringe pump via the catheter in the right atrium at a rate of $2 \mathrm{ml} / \mathrm{h}$ for $24 \mathrm{~h}$, commencing at the time of embolization. Loading doses were given immediately before embolization. There were seven treatment groups.

Group 1. Sterile isotonic saline was given to eight control animals.

Group 2. Sodium heparin (hog mucosa origin, approximately $120 \mathrm{U} / \mathrm{mg}$ based on protamine sulphate neutralization, M. T. C. Pharmaceuticals, Hamilton, Ontario, Canada) was given to six animals in a loading dose of $200 \mathrm{U} / \mathrm{kg}$ and a maintenance dose of $800 \mathrm{U} / \mathrm{kg} / 24 \mathrm{~h}$, which prolonged the partial thromboplastin time to 2-2.5 times control (cf. Results).

Groups 3-7 were given different regimens of SK (Streptase, lot 401, Hoechst Pharmaceuticals, Montreal, Quebec, Canada) designed to produce the following fibrinolytic effects, which are described in further detail under Results.

Group 3. SK was given to seven animals in "high" dose, viz, a loading dose of $250,000 \mathrm{U}$ over $10 \mathrm{~min}$ and a maintenance dose of $100,000 \mathrm{U} / \mathrm{h}$. This produced a moderate and sustained reduction in the euglobulin lysis time and a marked increase in the area of fibrin plate lysis and in the lysis of radioactive fibrin clots.

Group 4. SK was given to five animals in "low" dose, viz, a loading dose of $25,000 \mathrm{U}$ and a maintenance dose of $10,000 \mathrm{U} / \mathrm{h}$. This produced a moderate but transient reduction in the euglobulin lysis time. The lysis of radioactive fibrin clots was moderately increased after the loading dose and mildly increased thereafter.

Group 5. The same low dose of SK as in group 4, together with the same dose of heparin as in group 2, was given to four animals.

Group 6. SK was given to six animals in "very low" dose, viz. $5,000 \mathrm{U} / \mathrm{h}$ without a loading dose, together with the same dose of heparin as in group 2. This produced minimal changes in the euglobulin lysis time and a slight increase in the lysis of radioactive fibrin clots.

Group 7. SK was given to four animals in a "short" course, viz. the same loading dose as in group 3 but no maintenance dose, together with the same dose of heparin as in group 2. This produced a moderately shortened euglobulin lysis time at $1 \mathrm{~h}$ but no shortening thereafter.

\section{Assessment of residual embolus}

After $24 \mathrm{~h}$, each animal was given $4,000 \mathrm{U}$ of heparin intravenously and sacrificed by exsanguination from the wide-bore catheter in the right atrium. Exsanguination was continued until no further blood could be removed by syringe. The thoracic contents were removed en bloc, the heart and lungs were dissected and the macroscopic appearance of the embolus as far as the second order pulmonary arteries was recorded in detail and quantitated as described below. The whole lungs were then homogenized in $0.1 \mathrm{M}$ sodium hydroxide containing $20 \%$ urea in a final volume of approximately $400 \mathrm{ml}$ and triplicate aliquots of approximately $4 \mathrm{ml}$ were taken for counting. The amount of residual embolus was assessed both visually and by measuring the radioactivity in the lungs.

Visual method. The amount of visible embolus was scored on two separate occasions by two independent observers who had no knowledge either of the drug regimen given or of the measurements of lung radioactivity. The basis for scoring was a modification of a method recently described for the visual quantitation of lung scans (21). Each lung was divided into five approximately equal areas - upper lobe, middle lobe, medial and lateral parts of the lower lobe, and main pulmonary artery on each side. The 
amount of embolus in each area was assessed as completely filling the vessels (1 point), as incompletely filling the vessels $(0.5$ point $)$, or as not detectable ( 0 point $)$. The points for each area were summed to arrive at a total rating on a scale from 0 to 10 . In assessing the amount of residual embolus, there was agreement between the two assessors to within 0.5 point $83 \%$ of the time and to within 1 point $98 \%$ of the time. Similarly, the two assessors agreed with themselves, from one occasion to another, to within 0.5 point $88 \%$ of the time and to within 1 point $94 \%$ of the time.

Radioactive method. Radioactivity was assayed in an automatic gamma spectrometer (model 5212, Packard Instrument Co., Inc., Downers Grove, Ill.). The average deviation from the mean value for the counts of the triplicate lung aliquots was $\pm 5.5 \%$. It has previously been shown by one of the authors (30) and by Dellenbeck and Chien (31) that approximately $11 \%$ of the radioiodine label on canine fibrinogen is associated with fibrinopeptide $B$, which is split off from fibrinogen by thrombin on conversion to fibrin. It was considered invalid to regard the radioactivity associated with fibrinopeptide $\mathrm{B}$ as representing embolus; therefore, the amount of radioactivity representing the initial embolus was considered to be $89 \%$ of the amount of radioactivity initially injected. The amount of radioactivity remaining in the lungs was considered to represent residual embolus and was expressed as a percentage of the amount of radioactivity representing the initial embolus, i.e., $89 \%$ of injected radioactivity.

Serial measurements of circulating radioactivity were also made $1,2,3,4,5,6$, and $24 \mathrm{~h}$ after embolization. The total amount of radioactivity circulating at any one time was calculated by assuming a blood volume of $70 \mathrm{ml} / \mathrm{kg}$ of body wt. The amounts of thrombin-clottable and of trichloracetic acid-precipitable radioactivity were measured.

\section{Coagulation tests}

Blood was taken before and 1,4 , and $24 \mathrm{~h}$ after embolization for measurement of the following: hematocrit, platelet count (32), thrombin clotting time (TT) (33), activated partial thromboplastin time (PTT) (34), fibrinogen (35), plasminogen (36), euglobulin lysis time (37), area of fibrin plate lysis (38), paracoagulation phenomenon using the protamine sulphate test (39), titer of fibrin degradation products (FDP) using a tanned red cell hemagglutination inhibition assay (40) for which an antibody against canine fibrinogen had been raised in rabbits and adsorbed against canine serum, and SK resistance (24).

The systemic fibrinolytic state was also assessed by measuring the lysis of radioactive clots, a technique modified from that described by Alkjaersig, Fletcher, and Sherry (33). Briefly, 1-ml aliquots of pooled canine plasma containing approximately $1 \mu \mathrm{Ci}$ of ${ }^{125} \mathrm{I}$-labeled canine fibrinogen were clotted with thrombin. The clot was permitted to retract at $20^{\circ} \mathrm{C}$ for $6 \mathrm{~h}$ and then wound onto a wooden stick. The clot was immersed in $1 \mathrm{ml}$ of test plasma at $37^{\circ} \mathrm{C}$ for $30 \mathrm{~min}$ and then withdrawn. The amount of radioactivity released into the test plasma was calculated as a percentage of the total amount of radioactivity initially present in the clot.

\section{Assessment of bleeding}

In each animal, the amount of bleeding over $24 \mathrm{~h}$ from the cutdown sites was assessed semiquantitatively by the same observer without knowledge of the drug regimen be- ing used. The criteria for normal or abnormal bleeding were established after observations during an earlier study in untreated dogs (26). Bleeding was assessed from the time of suture of the cutdown sites. The amount of bleeding was considered normal if blood loss either did not occur or stopped within $5 \mathrm{~min}$ of suture.

\section{Statistical methods}

The degree of resolution of emboli in the different treatment groups was initially examined using a one-day analysis of variance (41). Each group was then compared with each of the other groups by using Duncan's "Multiple Range Test" (42) as modified by Kramer (43) to handle groups of unequal size. This is an appropriate test for comparing each of several treatment groups with each other, rather than the repeated use of the $t$ test (41) which gives incorrect significance levels in this situation.

\section{RESULTS}

Acute massive pulmonary embolism was produced in 45 animals. There was an acute mortality of $11 \%$, five animals dying within the first few minutes. Observations on the resolution of the emboli were made in the 40 surviving animals.

Comparison of visual and radioactive methods of assessing residual embolus. The assessment of the amount of residual embolus in each animal from macroscopic observations and from measurements of lung radioactivity is shown in Table $I$. There was close agreement in the average values for each treatment group and in addition, the individual results of the two methods were highly correlated $(r=0.82, P<$ $0.001)$. However, the radioactive method was considered to be the more precise, especially for smaller amounts of embolus, and was used for the detailed comparisons of the different treatment groups.

Degree of resolution of emboli. From the measurements of lung radioactivity, analysis of variance showed that there were highly significant differences in the percentage of residual embolus at $24 \mathrm{~h}$ among the seven treatment groups $(P<0.001)$. These differences were then examined in detail and each treatment group was compared with each of the other treatment groups by using Kramer's modification of Duncan's "Multiple Range Test."

In the control group (group 1), $49 \%$ of the initial amount of embolus remained at $24 \mathrm{~h}$. This was considerably more than in any of the other treatment groups and the difference between the control group and each of the six other groups was highly significant $(P<0.01)$.

Moderately increased resolution was seen after heparin (group 2) and low dose SK (group 4). Resolution was comparable among these two groups and each of these two groups showed significantly more resolution than the control group $(P<0.01)$ and significantly 
TABLE I

Amount of Residual Embolus

\begin{tabular}{|c|c|c|c|c|c|}
\hline Group & Treatment & Method & Results & Mean & SD \\
\hline 1 & Saline & $\begin{array}{l}\text { Radioactive } \\
\text { Visual }\end{array}$ & 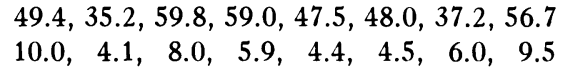 & $\begin{array}{r}49.1 \\
6.6\end{array}$ & $\begin{array}{l}9.3 \\
2.3\end{array}$ \\
\hline 2 & Heparin & $\begin{array}{l}\text { Radioactive } \\
\text { Visual }\end{array}$ & 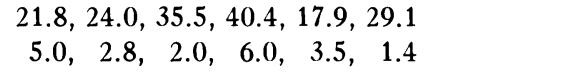 & $\begin{array}{r}28.1 \\
3.5\end{array}$ & $\begin{array}{l}8.6 \\
1.8\end{array}$ \\
\hline 3 & High dose SK & $\begin{array}{l}\text { Radioactive } \\
\text { Visual }\end{array}$ & 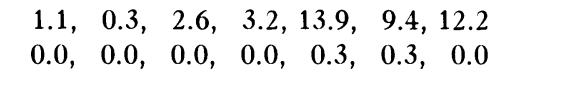 & $\begin{array}{l}6.1 \\
0.1\end{array}$ & $\begin{array}{l}5.6 \\
0.1\end{array}$ \\
\hline 4 & Low dose SK & $\begin{array}{l}\text { Radioactive } \\
\text { Visual }\end{array}$ & 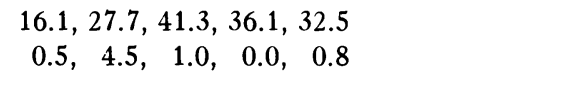 & $\begin{array}{r}30.7 \\
1.4\end{array}$ & $\begin{array}{l}9.6 \\
1.8\end{array}$ \\
\hline 5 & $\begin{array}{l}\text { Low dose SK } \\
+ \text { heparin }\end{array}$ & $\begin{array}{l}\text { Radioactive } \\
\text { Visual }\end{array}$ & 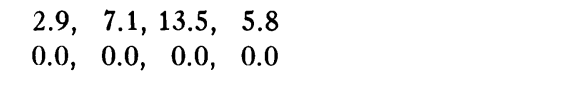 & $\begin{array}{l}7.3 \\
0.0\end{array}$ & $\begin{array}{l}4.5 \\
0.0\end{array}$ \\
\hline 6 & $\begin{array}{l}\text { Very low dose SK } \\
\quad+\text { heparin }\end{array}$ & $\begin{array}{l}\text { Radioactive } \\
\text { Visual }\end{array}$ & 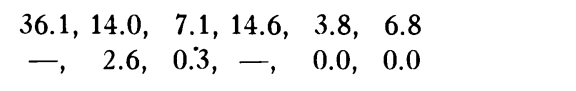 & $\begin{array}{r}13.7 \\
0.7\end{array}$ & $\begin{array}{r}11.8 \\
1.3\end{array}$ \\
\hline 7 & $\begin{array}{l}\text { Short course SK } \\
+ \text { heparin }\end{array}$ & $\begin{array}{l}\text { Radioactive } \\
\text { Visual }\end{array}$ & 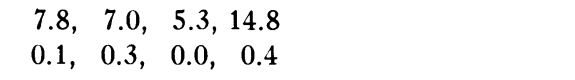 & $\begin{array}{l}8.7 \\
0.2\end{array}$ & $\begin{array}{l}4.2 \\
0.2\end{array}$ \\
\hline
\end{tabular}

Groups and treatments are as outlined in the text. The results obtained by using the radioactive method are in percent of initial embolus; the results obtained by using the visual method are on a scale from 0 to 10 . The dash indicates that visual assessment was not made because of postmortem clot formation.

less resolution than each of the other four treatment groups $(P<0.01)$.

Virtually complete resolution was seen after high dose SK (group 3), low dose SK plus heparin (group 5 ), very low dose SK plus heparin (group 6) and short course SK plus heparin (group 7). Resolution was comparable among these four groups and, as noted above, was highly significantly more than in the control group $(P<0.01)$ or in either of the other two treatment groups $(P<0.01)$.

Released radioactivity. The difference in the amounts of lysis between the various treatment groups was also reflected in the serial levels of circulating radioactivity (Figs. 1 and 2), but the inhomogeneity and hence different clearance rates of the breakdown products of fibrin preclude any more exact calculations. These measurements also provided general information on the time-course of lysis of the emboli. Over $80 \%$ of the circulating radioactivity was in the trichloracetic acidprecipitable fraction of the plasma and none was thrombin clottable. The level of circulating radioactivity at $1 \mathrm{~h}$ and over the $24-\mathrm{h}$ period corresponded to the amount of lysis of the embolus as demonstrated by the measurement of residual radioactivity in the lungs. Animals given high loading doses of SK (groups 3 and 7) showed the highest early peak of released radioactivity, suggesting that much of the lysis demonstrated at $24 \mathrm{~h}$ had in fact occurred within the first few hours. After low loading doses of SK (groups 4 and 5) there was a moderate early peak of released radioactivity. In animals given either heparin or heparin plus very low dose SK (groups 2 and 6) there was no early peak but a more sustained plateau of released radioactivity, suggesting that the amount of lysis demonstrated at $24 \mathrm{~h}$ had occurred more gradually.

The significance of the differences in the amounts of released radioactivity among the seven different treat-

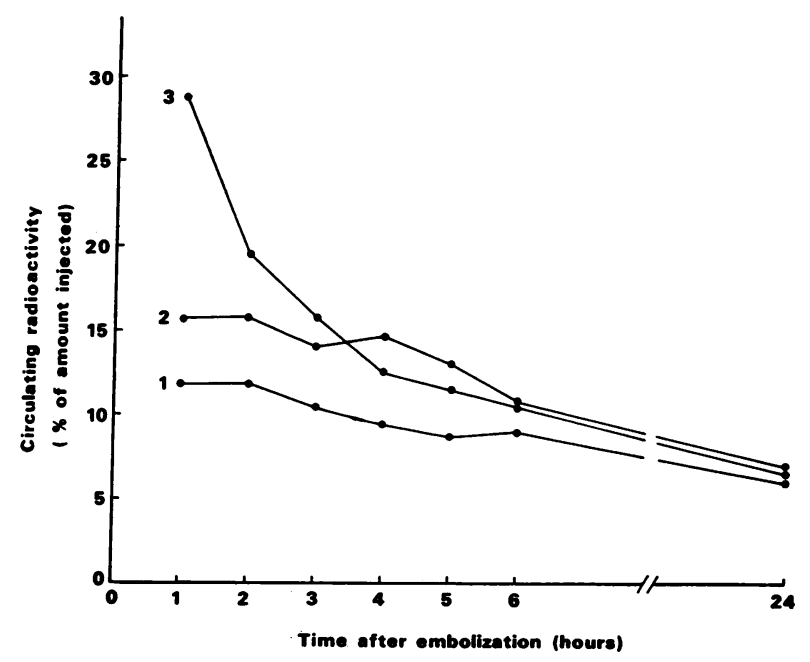

FIGURE 1 Serial measurements of circulating radioactivity in animals given saline, heparin, or SK. Treatment groups $(1,2$, and 3$)$ are as described previously. 
TABLE II

Resulis of Coagulation Tests

\begin{tabular}{crcccccc}
\hline Group & Test & Before & \multicolumn{2}{c}{$1 \mathrm{~h}$} & \multicolumn{2}{c}{$4 \mathrm{~h}$} & $24 \mathrm{~h}$ \\
\hline 1 & PTT & $15.4(0.6)$ & $18.6(0.5)$ & $18.8(1.0)$ & $16.8(1.1)$ \\
& TT & $13.1(0.9)$ & $15.4(0.8)$ & 16.2 & $(1.1)$ & $12.1 \quad(1.1)$ \\
2 & PTT & $15.0(1.0)$ & $78.2(16.8)$ & 31.7 & $(4.4)$ & $39.7(13.6)$ \\
& TT & $11.0(0.6)$ & $90.0(-)$ & $68.8(9.4)$ & $40.7(15.8)$ \\
3 & PTT & $14.1(0.4)$ & $18.4(0.7)$ & $19.1(1.2)$ & $16.5(0.6)$ \\
& TT & $13.1(0.7)$ & $15.3(1.1)$ & 16.1 & $(0.9)$ & $12.5 \quad(0.8)$ \\
4 & PTT & $13.4(0.7)$ & $17.2(0.9)$ & $17.8(1.2)$ & $16.8(0.8)$ \\
& TT & $11.8(0.7)$ & $12.8(1.1)$ & $12.6(1.2)$ & $10.2(0.7)$ \\
5 & PTT & $18.3(0.6)$ & $98.5(13.5)$ & $39.3(4.6)$ & $78.8(19.2)$ \\
& TT & $11.0(0.4)$ & $90.0(-)$ & $80.5(5.5)$ & $90.0(-)$ \\
6 & PTT & $19.3(0.5)$ & $101.5(12.7)$ & $91.0(10.2)$ & $41.0(8.5)$ \\
& TT & $13.0(0.0)$ & $90.0(-)$ & $90.0(-)$ & $50.0(18.0)$ \\
7 & PTT & $16.0(0.0)$ & $48.5(11.5)$ & $38.0(5.0)$ & $78.5(9.5)$ \\
& TT & $13.0(1.0)$ & $90.0(-)$ & 46.5 & $(0.5)$ & $90.0(-)$ \\
\hline
\end{tabular}

Treatment groups and tests are as outlined in the text. "Before," " $1 \mathrm{~h}$, ," " $4 \mathrm{~h}$," and " $24 \mathrm{~h}$ " refer to time before and at intervals after embolization. Results are mean values with standard error in parentheses. PTT and TT are in seconds; the dash indicates that calculation of a measure of variation was inappropriate, since all values exceeded an arbitrary upper limit of $90 \mathrm{~s}$ for TT.

ment groups was also assessed by using Kramer's modification of Duncan's "Multiple Range Test." Control animals (group 1) showed significantly less released radioactivity $(P<0.05)$ at $1 \mathrm{~h}$ than animals given high dose SK (group 3), low dose SK plus heparin (group 5), or short course SK plus heparin (group

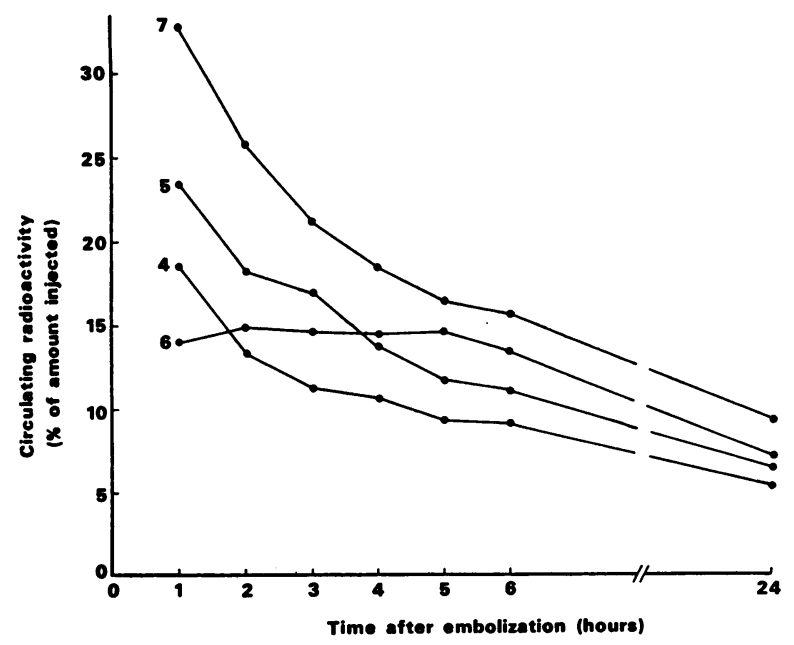

FIGURE 2 Serial measurements of circulating radioactivity in animals given different regimens of $\mathrm{SK}$ with and without heparin. Treatment groups $(4,5,6$, and 7$)$ are as described previously.
7). Control animals were not significantly different from animals given heparin (group 2), low dose SK (group 4), or very low dose SK plus heparin (group 6).

Coagulation findings. Both the PTT and TT showed a marked increase in animals given heparin (groups 2, 5,6 , and 7) but little change in the other groups (Table II). There were no significant differences between SKtreated and control animals in TT or plasma fibrinogen but serum FDP levels were higher in animals given high dose SK than in any other treatment group.

Systemic fibrinolytic activity showed a sustained increase in animals given high dose SK (Fig. 3). Animals given low dose and short course SK showed a transient increase in fibrinolytic activity (Fig. 4). It was not possible to quantitate accurately the minimal fibrinolytic effect of very low dose SK by using the euglobulin lysis time. This effect was therefore examined by using the radioactive clot lysis test and was compared with the effect in animals given low dose and high dose SK (Fig. 5). This test demonstrated a dose-response relation for the three SK regimens, with mildly increased systemic fibrinolytic activity in animals given very low dose SK, a greater increase in those given low dose $\mathrm{SK}$, and the greatest increase in those given high dose SK.

The plasma plasminogen level remained unchanged except in animals given high dose SK, in which is 
showed a moderate and progressive fall from an initial level of 3.6 Committee on Thrombolytic Agents (CTA) $\mathrm{U} / \mathrm{ml}$ to $2.6 \mathrm{CTA} \mathrm{U} / \mathrm{ml}$ at $24 \mathrm{~h}$. The protamine sulphate test and hematocrit showed no significant changes after embolism in any group. The mean SK resistance was $55,000 \mathrm{U}$ (SD 19,000 U).

A progressive and significant fall in platelet count was noted in saline-treated animals. The mean platelet count was $81 \%$ of the pre-embolism value after $1 \mathrm{~h}$ $(P<0.05), 79 \%$ after $4 \mathrm{~h}(P<0.01)$, and $62 \%$ after $24 \mathrm{~h}(P<0.005)$. There were no significant changes in platelet count after embolism in heparin-treated animals.

Assessment of bleeding. The distinction between normal and abnormal bleeding was always clear-cut with the criteria outlined above. Abnormal bleeding from cutdown sites usually lasted several hours and was noted in none of the control animals, one of six animals given heparin, three of seven animals given high dose SK, two of six animals given very low dose SK and heparin, and two of four animals given short course SK and heparin.

Postmortem findings. Postmortem examination of the lungs was made in each animal. The lungs appeared pale and no blood was noted in the pulmonary arterial tree, confirming the thoroughness of exsanguination. Large pulmonary hemorrhages were seen in four of the seven animals given high dose SK but in none of the animals in any other treatment group. In the other three of these seven animals (in each of which a pulmonary artery catheter had been inserted briefly for initial pressure measurements) there were hemorrhagic areas in the right ventricular myocardium but no myocardial hemorrhages were seen in catheterized animals in any other treatment group.

\section{DISCUSSION}

The principles of thrombolytic therapy have been established by the fundamental studies of Fletcher, Sherry, and Alkjaersig $(33,44-48)$ and the thrombolytic agents SK and urokinase have been extensively investigated in both experimental (9-13) and clinical (14-21) venous thrombosis and pulmonary embolism. However, the optimal dosage regimen of thrombolytic drugs such as SK is still uncertain. SK is usually given in a standard high dose regimen which produces and maintains plasminogen depletion $(24,25)$, a therapeutic approach which has two major shortcomings: (a) hemorrhage, which can at times be serious, is common in patients with recent vascular trauma $(18,25) ;(b)$ if rethrombosis occurs while the circulating plasminogen is depleted, the recurrent thrombus is likely to be resistant to lysis (11). Although rethrombosis may be prevented by the anticoagulant effect of a high titer of fibrin split products, the decline of this titer towards normal is unpredictable and the patient may be unprotected for a variable length of time. Concomitant heparin administration is considered inadvisable since it could aggravate an already high risk of bleeding.

Alternative regimens of thrombolytic therapy which do not have these limitations would clearly be desirable. However, it would be difficult to evaluate the relative efficacy of a number of different therapeutic regimens in clinical pulmonary embolism because of the problem of obtaining sufficient numbers of cases suitable for detailed investigation.

For these reasons, it was decided to evaluate a number of different regimens for SK therapy in acute experimental pulmonary embolism. Difficulties, however, have been experienced with the quantitation of experimental pulmonary emboli $(13,26,49,50)$. Pulmonary angiography $(13,49-52)$ and lung scanning $(50,52$, 53) are semiquantitative and postmortem recovery of the embolic material $(50,51,54,55)$ while more quantitative may fail to include the emboli from all the very small vessels. We have therefore used an alternative method which permitted more accurate quantitation of the degree of resolution of experimental pulmonary emboli.

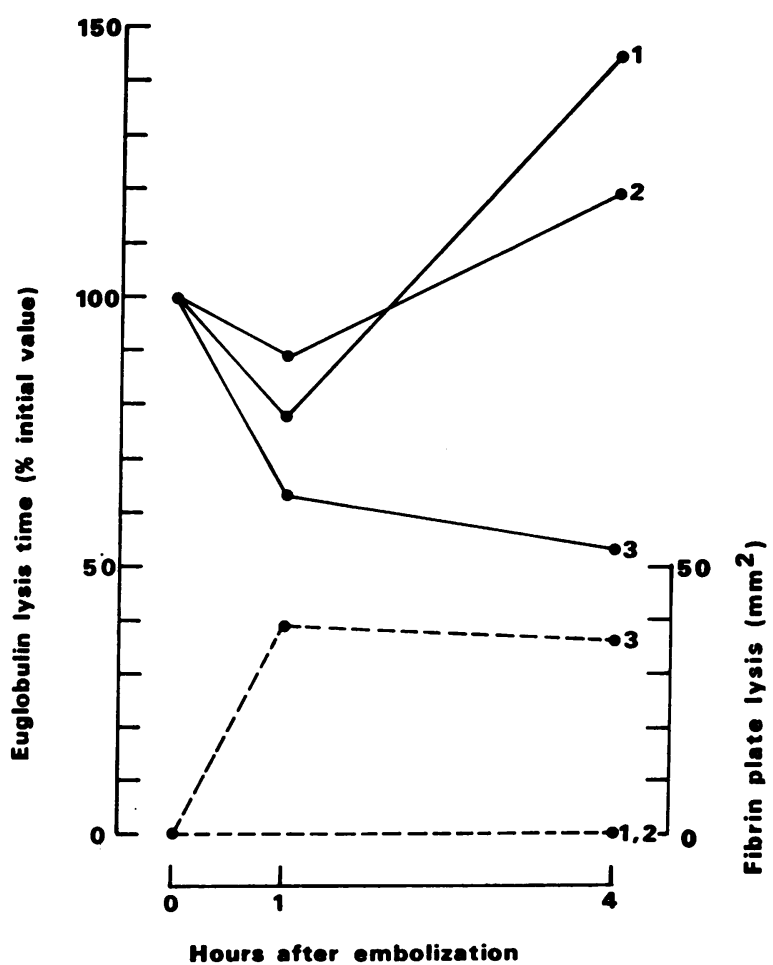

FIgURE 3 Serial measurements of fibrinolytic state in animals given saline, heparin, or SK. Treatment groups $(1,2$, and 3$)$ are as described previously.

Resolution of Pulmonary Emboli 


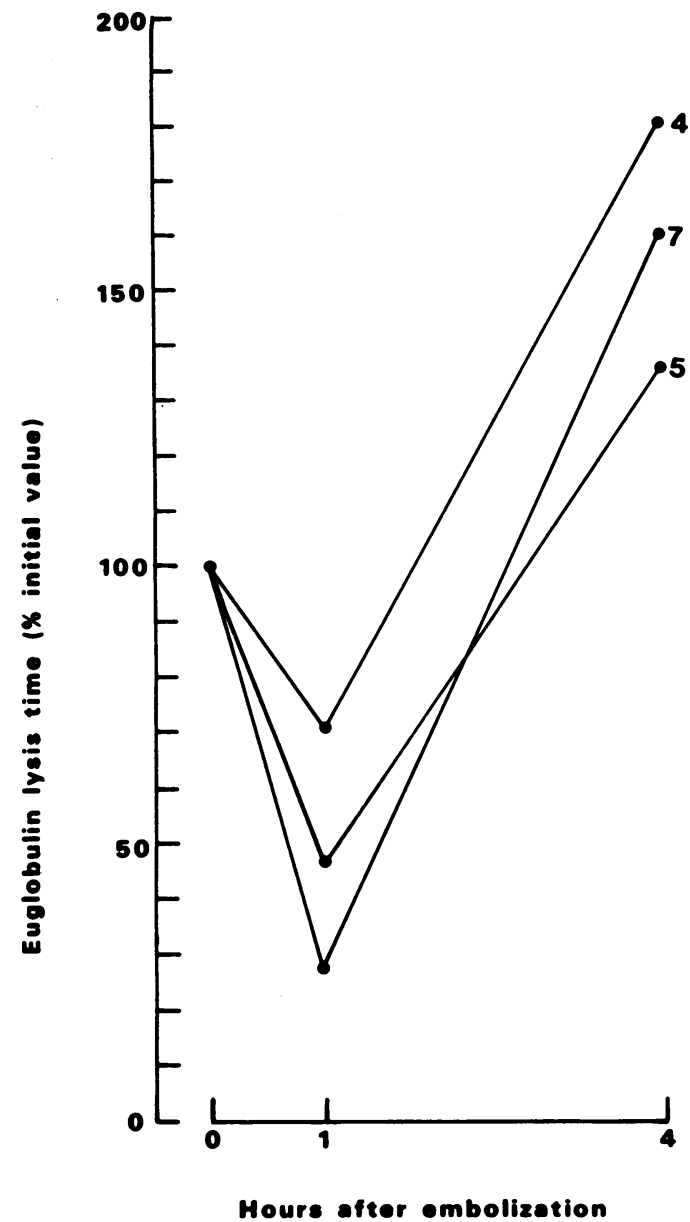

Figure 4 Serial measurements of fibrinolytic state in animals given different regimens of $\mathrm{SK}$ with and without heparin. Treatment groups $(4,5$, and 7$)$ are as described previously.

In the present study, the amount of resolution of pulmonary emboli was assessed by counting residual radioactivity in exsanguinated homogenized lungs. This method was compared with independent, quantitative visual assessment of the amount of embolus found at postmortem examination. While the individual results of the two methods were highly correlated and the average results of the two methods were similar for each treatment group, the visual method was considered to be less precise because of the difficulty in visually detecting all emboli in smaller vessels. The radioactive method was therefore used for the detailed analyses of the different treatment regimens.

The radioactive method has the theoretical limitation that it includes some circulating radioactivity in the calculated amount of residual embolus. However, since the total amount of circulating radioactivity in each group at the end of the experiment was only 5-10\% of the initial radioactivity, if one assumes a pulmonary blood volume of approximately $20 \%$ of the total blood volume, only $1-2 \%$ of the initial radioactivity could have been present in the pulmonary circulation before exsanguination. Thus, after exsanguination, the overestimate of residual pulmonary embolus due to the presence of the soluble radioactive fragments is probably less than $1 \%$ of the initial radioactivity.

The present experimental method also has the limitation that it uses an in vitro clot rather than an in vivo thrombus for embolization. However, the structure and dimensions of this type of in vitro clot are comparable to those of large, recent, peripheral venous thrombi which are considered to be the cause of most major clinical pulmonary emboli (56). Furthermore, the amount of resolution of emboli in control animals in the present study was similar to the degree of resolution described by others for emboli derived from in vivo thrombi in dogs $(13,55)$. Finally, there was a progressive fall in platelet count in control animals but not in heparin-treated animals, a finding comparable with observations made by Thomas and associates (57-59) using experimental emboli derived from in vivo thrombi.

In control animals, approximately half of the embolus remained after $24 \mathrm{~h}$, confirming observations by others that in the dog there are effective mechanisms for the removal of emboli from the lungs $(12,13,54,55,60-62)$. Compared to control animals, heparin-treated dogs showed considerably enhanced resolution of emboli after $24 \mathrm{~h}$. Heparin was given in a dose which was comparable on a body weight basis to the dose commonly used in man and which prolonged the partial thromboplastin time to approximately $2-2.5$ times control.

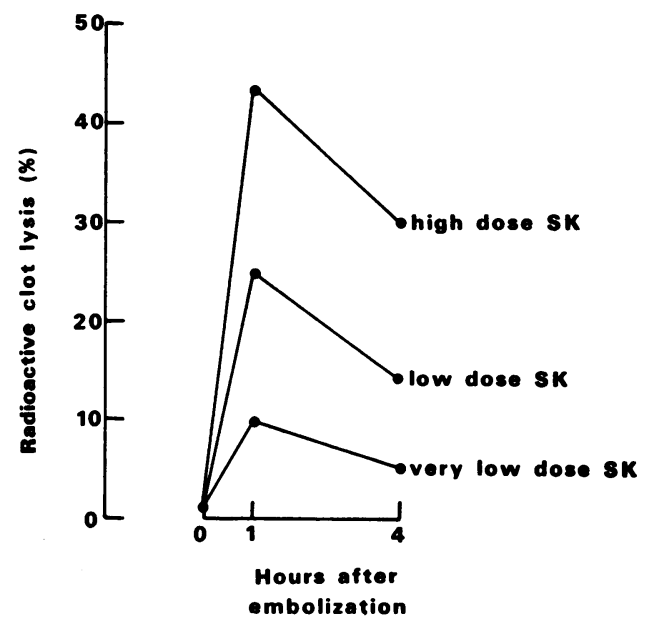

Figure 5 Comparison of radioactive clot lysis in vitro by plasma from animals given different regimens of SK. 
Heparin has been previously reported to decrease the size of experimental venous thrombi and pulmonary emboli (63-65). The mechanisms by which heparin could produce this effect include (a) prevention of deposition of new fibrin onto the embolus, thus facilitating spontaneous resolution $(63,64,66-69),(b)$ inhibition of thrombin-induced platelet release and aggregation, thus preventing accretion of platelets on the surface of the embolus (57-59), and (c) a direct thrombolytic effect $(65,70,71)$.

In our study, heparin had no fibrinolytic effect as reflected by tests of systemic fibrinolytic activity. However, our results are consistent with observations made by others that platelets are deposited onto recent pulmonary emboli, an effect which is inhibited by heparin (57-59). It is suggested that the enhanced resolution of pulmonary emboli in heparin-treated animals may have been due to the reduction by heparin of fibrin and platelet deposition onto the embolus, thus facilitating natural resolution.

The present study demonstrated that in experimental pulmonary embolism a number of different regimens of SK combined with heparin were as effective as standard high doses of SK. Thus, the combination of low dose, very low dose, or short course SK, combined with heparin, produced as much resolution as high dose SK alone. The synergistic effect of heparin on low doses and short courses of SK can probably be explained by the prevention by heparin of further deposition of fibrin on the embolus.

Cutaneous hemorrhages were common in animals given high dose SK or any dose of SK combined with heparin. Extensive pulmonary and myocardial hemorrhages were seen in all animals given high dose SK but in none of the other treatment groups, suggesting that combined therapy might be associated with a lower risk of visceral hemorrhage.

It is uncertain how far our experimental findings can be extended to the clinical situation. The present model has several potential limitations, including species differences between dog and man in the natural history of pulmonary emboli, the use of an in vitro clot rather than an in vivo thrombus, and the relative resistance of canine plasminogen to activation by SK (72). Nevertheless, the results are sufficiently promising to suggest that alternative regimens of thrombolytic therapy should be explored clinically. Preliminary observations on the clinical use of combined therapy with low dose SK and full dose heparin in patients with angiographically proven iliofemoral venous thrombosis and pulmonary embolism have been encouraging and have demonstrated the safety and feasibility of such a regimen (73). Since heparin may have beneficial effects through inhibition of some of the bronchial and vascu- lar responses to emboli $(57-59,74,75)$, the use of heparin in full dosage in combination with a modified SK regimen in an attractive therapeutic possibility in pulmonary embolism.

\section{ACKNOWLEDGMENTS}

The authors thank Miss Theresa Clinton for her technical assistance in performing the coagulation tests.

This work was supported by the Medical Research Council of Canada, the Ontario Department of Health, the Ontario Heart Association, and Canadian Hoechst Limited.

\section{REFERENCES}

1. Cade, J. F., D. M. Hynes, E. Regoeczi, and J. Hirsh. 1972. Effective thrombolysis by streptokinase in low dosage. Circ. 46 Suppl. 2: 54. (Abstr.)

2. Bauer, G. 1946. Thrombosis: early diagnosis and abortive treatment with heparin. Lancet. 1: 447-454.

3. Bauer, G. 1964. Clinical experiences of a surgeon in the use of heparin. Am. J. Cardiol. 14: 29-35.

4. Murray, G. 1947. Anticoagulant therapy with heparin. Am. J. Med. 3 : 468-471.

5. O'Sullivan, E. F., J. Hirsh, R. A. McCarthy, and G. C. de Gruchy. 1968. Heparin in the treatment of venous thrombo-embolic disease: Administration, control and results. Med. J. Aust. 2: 153-159.

6. Basu, D., A. Gallus, J. Hirsh, and J. Cade. 1972. A prospective study of the value of monitoring heparin treatment with the activated partial thromboplastin time. N. Engl. J. Med. 287: 324-327.

7. Barritt, D. W., and S. C. Jordan. 1960. Anticoagulant drugs in the treatment of pulmonary embolism. A controlled trial. Lancet. 1 : 1309-1312.

8. Sherry, S. 1968. Fibrinolysis. Annu. Rev. Med. 19: 247-268.

9. Johnson, A. J., and W. S. Tillett. 1952. The lysis in rabbits of intravascular blood clots by the streptococcal fibrinolytic system (streptokinase). J. Exp. Med. 95: 449-464.

10. Sherry, S., A. Titchener, L. Gottesman, P. Wasserman, and W. Troll. 1954. The enzymatic dissolution of experimental arterial thrombi in the dog by trypsin, chymotrypsin and plasminogen activators. J. Clin. Invest. 33: 1303-1313.

11. Johnson, A. J., and W. R. McCarty. 1959. The lysis of artificially induced intravascular clots in man by intravenous infusions of streptokinase. J. Clin. Invest. 38: 1627-1643.

12. Browse, N. L., and D. C. O. James. 1964. Streptokinase and pulmonary embolism. Lancet. 2: 1039-1043.

13. Genton, E., and P. S. Wolf. 1967. Experimental pulmonary embolism: effects of urokinase therapy on organizing thrombi. J. Lab. Clin. Med. 70: 311-325.

14. Hirsh, J., G. S. Hale, I. G. McDonald, R. A. McCarthy, and J. F. Cade. 1967. Resolution of acute massive pulmonary embolism after pulmonary arterial infusion of streptokinase. Lancet. 2: 593-597.

15. Sasahara, A. A., J. E. Cannilla, J. S. Belko, R. I. Morse, and A. J. Criss. 1967. Urokinase therapy in clinical pulmonary embolism. A new thrombolytic agent. N. Engl. J. Med. 277: 1168-1173.

16. Sautter, R. D., D. A. Emanuel, F. W. Fletcher, F. J. Wenzel, and J. I. Matson. 1967. Urokinase for the 
treatment of acute pulmonary thromboembolism. JAMA J. Am. Med. Assoc. 202: 215-218.

17. Genton, E., and P. S. Wolf. 1968. Urokinase therapy in pulmonary thromboembolism. Am. Heart J. 76: 628-637.

18. Hirsh, J., G. S. Hale, I. G. McDonald, R. A. McCarthy, and A. Pitt. 1968. Streptokinase therapy in acute major pulmonary embolism. Effectiveness and problems. Br. Med. J. 4:729-734.

19. Miller, G. A. H., R. V. Gibson, M. Honey, and G. C. Sutton. 1969. Treatment of pulmonary embolism with streptokinase. A preliminary report. $B r$. Med J. 1: 812-815.

20. Hirsh, J., I. G. McDonald, and G. S. Hale. 1970. Streptokinase therapy in acute major pulmonary embolism. Am. Heart J. 79: 574-578.

21. The urokinase pulmonary embolism trial. 1973. Circulation XLVII. Monograph no. 39. American Heart Association, New York.

22. Vellar, I. D., and E. F. O'Sullivan. 1972. Comparison of the action of heparin and streptokinase on experimental pulmonary emboli in the dog. Cardiovasc. Res. 6: 734 740.

23. Hirsh, J., I. G. McDonald, G. A. Hale, E. F. O'Sullivan, and V. M. Jelinek. 1971. Comparison of the effects of streptokinase and heparin on the early rate of resolution of major pulmonary embolism. Can. Med. Assoc. J. 104 : 488-491.

24. Verstraete, M., J. Vermylen, A. Amery, and C. Vermylen. 1966. Thrombolytic therapy with streptokinase using a standard dosage scheme. Br. Med. J. 1: 454-456.

25. Hirsh, J., E. F. O'Sullivan, and M. Martin. 1970. Evaluation of a standard dosage schedule with streptokinase. Blood J. Hematol. 35 : 341-349.

26. Cade, J. F., D. M. Hynes, E. S. Garnett, E. Regoeczi, and J. Hirsh. 1974. Hot clot scan: a method for the accurate identification of experimental pulmonary emboli. Invest. Radiol. 9 : 32-36.

27. Regoeczi, E. 1970. Fibrinogen catabolism: kinetics of catabolism following sudden elevation of the pool with exogenous fibrinogen. Clin. Sci. (Oxf.). 38: 111-121.

28. McFarlane, A. S. 1958. Efficient trace-labelling of proteins with iodine. Nature (Lond.). $182: 53$.

29. Just-Viera, J. O., and G. H. Yeager. 1964. Massive pulmonary embolism: II. Predictable mortality and cardiopulmonary changes in dogs breathing room air. Ann. Surg. 159 : 636-644.

30. Regoeczi, E., and P. L. Walton. 1967. Effects of clotting on the label in iodinated fibrinogen in different species. Thromb. Diath. Haemorrh. 17: 237-246.

31. Dellenbeck, R. J., and S. Chien. 1971. The quantitation of isotope loss with tyrosine loss in the canine fibrinogen-fibrin transformation. Proc. Soc. Exp. Biol. Med. $137:$ 751-758.

32. Brecher, G., and E. P. Cronkite. 1950. Morphology and enumeration of human blood platelets J. Appl. Physiol. $3: 365-377$.

33. Alkjaersig, N., A. P. Fletcher, and S. Sherry. 1959. The mechanism of clot dissolution by plasmin. J. Clin. Invest. 38: 1086-1095.

34. Proctor, R. R., and S. I. Rapaport. 1961. The partial thromboplastin time with kaolin. Am. J. Clin. Pathol. 36: 212-219.

35. Astrup, T., P. Brakman, and U. Nissen. 1965. The estimation of fibrinogen. A revision. Scand. J. Clin. Lab. Invest. $17:$ 57-65.
36. Johnson, A. J., D. L. Kline, and N. Alkjaersig. 1969. Assay methods and standard preparations of plasmin, plasminogen and urokinase in purified systems, 19671968. Thromb. Diath. Haemorrh. 21: 259-272.

37. Buckell, M. 1958. The effect of citrate on euglobulin methods of estimating fibrinolytic activity. J. Clin. Pathol. 11: 403-405.

38. Bishop, R., H. Ekert, G. Gilchrist, E. Shanbrom, and L. Fekete. 1970. The preparation and evaluation of a standardized fibrin plate for the assessment of fibrinolytic activity. Thromb. Diath. Haemorrh. 23: 202-210.

39. Niewiarowski, S., and V. Gurewich. 1971. Laboratory identification of intravascular coagulation. The serial dilution protamine sulphate test for the detection of fibrin monomer and fibrin degradation products. $J$. Lab. Clin. Med. $77:$ 665-676.

40. Merskey, C., P. Lalezari, and A. J. Johnson. 1969. A rapid, simple, sensitive method for measuring fibrinolytic split products in human serum. Proc. Soc. Exp. Biol. Med. 131: 871-875.

41. Armitage, P. 1971. Statistical Methods in Medical Research. John Wiley and Sons, Inc., New York.

42. Duncan, D. B. 1955. Multiple range and multiple F tests. Biometrics. $11: 1-42$.

43. Kramer, C. Y. 1956. Extension of multiple range tests to group means with unequal numbers of replications. Biometrics. 12: 307-310.

44. Fletcher, A. P., N. Alkjaersig, and S. Sherry. 1959. The maintenance of a sustained thrombolytic state in man. I. Induction and effects. J. Clin. Invest. 38: 10961110.

45. Fletcher, A. P., S. Sherry, N. Alkjaersig, F. E. Smyrniotis, and S. Jick. 1959. The maintenance of a sustained thrombolytic state in man. II. Clinical observations on patients with myocardial infarction and other thromboembolic disorders. J. Clin. Invest. 38: 11111119.

46. Fletcher, A. P., N. Alkjaersig, and S. Sherry. 1962. Fibrinolytic mechanisms and the development of thrombolytic therapy. Am. J. Med. 33: 738-752.

47. Sherry, S., A. P. Fletcher, and N. Alkjaersig. 1959. Developments in fibrinolytic therapy for thrombo embolic disease. Ann. Intern. Med. 50: 560-570.

48. Sherry, S., R. I. Lindemeyer, A. P. Fletcher, and N. Alkjaersig. 1959. Studies on enhanced fibrinolytic activity in man. J. Clin. Invest. 38: 810-822.

49. Dalen, J. E., V. S. Mathur, H. Evans, F. W. Haynes, A. A. Pur-Shahriari, P. D. Stein, and L. Dexter. 1966. Pulmonary angiography in experimental pulmonary embolism. Am. Heart J. 72 : 509-520.

50. Moser, K. M., J. Rius-Garriga, G. C. Hajjar, and G. A. Landis. 1967. Correlation of angiographic-radiophotoscan-autopsy findings in experimental pulmonary embolism. Clin. Res. 15: 75. (Abstr.)

51. Stein, P. D., J. F. O'Connor, J. E. Dalen, A. A. Pur-Shahriari, F. G. Hoppin, Jr., D. T. Hammond, F. W. Haynes, F. G. Fleischner, and L. Dexter. 1967. The angiographic diagnosis of acute pulmonary embolism. Evaluation of criteria. Am. Heart J. 73: 730-741.

52. Moser, K. M., P. Harsanyi, G. Rius-Garriga, M. Guisan, G. A. Landis, and A. Miale, Jr. 1969. Assessment of pulmonary photoscanning and angiography in experimental pulmonary embolism. Circulation. 39: 663-674.

53. Moser, K. M., and A. Miale. 1968. Interpretative pitfalls in lung photoscanning. Am. J. Med. 44: 366-376. 
54. Freiman, D. G., S. Wessler, and M. Lertzman. 1961. Experimental pulmonary embolism with serum-induced thrombi aged in vivo. Am. J. Pathol. 39: 95-102.

55. Wessler, S., D. G. Freiman, J. D. Ballon, J. H. Katz, R. Wolff, and E. Wolf. 1961. Experimental pulmonary embolism with serum-induced thrombi. Am. J. Pathol. $38: 89-101$.

56. Hume, M., S. Sevitt, and D. P. Thomas. 1970. Venous Thrombosis and Pulmonary Embolism. Harvard University Press, Cambridge, Mass.

57. Thomas, D. P., G. Tanabe, M. Khan, and M. Stein. 1965. Humoral factors mediated by platelets in experimental pulmonary embolism. In Pulmonary Embolic Disease. A. A. Sasahara and M. Stein, editors. Grune \& Stratton, Inc., New York. 59-64.

58. Thomas, D. P., V. Gurewich, and T. P. Ashford. 1966. Platelet adherence to thromboemboli in relation to the pathogenesis and treatment of pulmonary embolism. N. Engl. J. Med. 274 : 953-956.

59. Gurewich, V., M. L. Cohen, and D. P. Thomas. 1968. Humoral factors in massive pulmonary embolism: an experimental study. Am. Heart J. 76: 784-794.

60. Allison, P. R., M. S. Dunnill, and R. Marshall. 1960. Pulmonary embolism. Thorax. 15: 273-283.

61. Marshall, R., D. C. Sabiston, P. R. Allison, A. R. Bosman, and M. S. Dunnill. 1963. Immediate and late effects of pulmonary embolism by large thrombi in dogs. Thorax. 18: 1-9.

62. Marshall, R., and M. S. Dunnill. 1966. Experimental pulmonary embolism by platelet agglutinates in dogs. Thorax. 21 : 372-381.

63. Rabinovitch, J., and B. Pines. 1943. Effect of heparin on experimentally produced venous thrombosis. Surgery (St. Louis). 14 : 669-678.

64. Lewis, J. H., C. W. Kerber, and J. H. Wilson. 1964. Effects of fibrinolytic agents and heparin on intravascular clot lysis. Am. J. Physiol. 207: 1044-1048.
65. Fitz Gerald, D. E., I. L. F. Szeto, J. Spero, and J. H. Lewis. 1967. The thrombolytic effect of heparin and a heparin-like substance SI' 54. Thromb. Diath. Hacmorrh. 17: 418-422.

66. Mason, E. C. 1924. Blood coagulation. The production and prevention of experimental thrombosis and pulmonary embolis. Surg. Gynecol. Obst. 39: 421-428.

67. Wright, H. P., M. M. Kubik, and M. Hayden. 1952. Influence of anticoagulant administration on the rate of recanalization of experimentally thrombosed veins. $\mathrm{Br}$. J. Surg. 40: 163-166.

68. Carey, L. C., and R. D. Williams. 1960. Comparative effects of dicumarol, tromexan and heparin on thrombus propagation. Ann. Surg. 152: 919-922.

69. Walker, R. H. S., J. A. Jackson, and J. Goodwin. 1970. Resolution of pulmonary embolism. Br. Med. J. 4: 135139.

70. Silver, D., and J. H. Hall. 1966. Effect of heparin on the fibrinolytic system. Surg. Forum. 17: 11-13.

71. Olwin, J. H., and J. L. Koppel. 1967. Little publicized aspects of thromboembolism. Med. Clin. North Am. 51: 151-159.

72. Baillie, A. J., and A. K. Sim. 1971. Activation of the fibrinolytic enzyme system in laboratory animals and in man. A comparative study. Thromb. Diath. Haemorrh. 25: 499-506.

73. Turpie, A. G. G., A. S. Gallus, J. Hirsh, and J. F. Cade. 1973. Thrombolysis with a combination of small doses of streptokinase and full dose heparin. Proceedings of the IVth International Congress on Thrombosis and Haemostasis, Vienna. 413. (Abstr.)

74. Gurewich, V., D. Thomas, M. Stein, and S. Wessler. 1963. Bronchoconstriction in the presence of pulmonary embolism. Circulation. $27: 339-345$.

75. Thomas, D., M. Stein, G. Tanabe, V. Rege, and S. Wessler. 1964. Mechanism of bronchoconstriction produced by thromboemboli in dogs. Am. J. Physiol. 206: 1207-1212. 